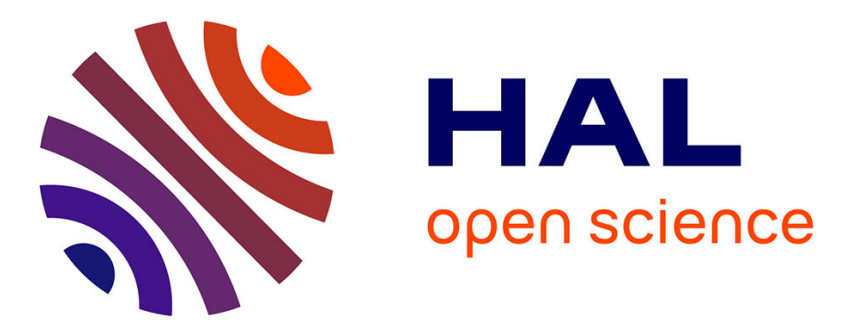

\title{
Monitoring conformational landscape of ovine prion protein monomer using ion mobility coupled to mass spectrometry
}

Guillaume van Der Rest, Human Rezaei, Frederic Halgand

\section{To cite this version:}

Guillaume van Der Rest, Human Rezaei, Frederic Halgand. Monitoring conformational landscape of ovine prion protein monomer using ion mobility coupled to mass spectrometry. Journal of The American Society for Mass Spectrometry, 2017, 28 (2), pp.303-314. 10.1007/s13361-016-1522-x . hal-01604181

\section{HAL Id: hal-01604181 \\ https://hal.science/hal-01604181}

Submitted on 27 May 2020

HAL is a multi-disciplinary open access archive for the deposit and dissemination of scientific research documents, whether they are published or not. The documents may come from teaching and research institutions in France or abroad, or from public or private research centers.
L'archive ouverte pluridisciplinaire HAL, est destinée au dépôt et à la diffusion de documents scientifiques de niveau recherche, publiés ou non, émanant des établissements d'enseignement et de recherche français ou étrangers, des laboratoires publics ou privés. 


\title{
Monitoring Conformational Landscape of Ovine Prion Protein Monomer Using Ion Mobility Coupled to Mass Spectrometry
}

\author{
Guillaume Van der Rest, ${ }^{1}$ Human Rezaei, ${ }^{2}$ Frédéric Halgand ${ }^{1}$ [C \\ ${ }^{1}$ Laboratoire de Chimie Physique, Université Paris Sud, CNRS UMR 8000, 91405, Orsay, France \\ ${ }^{2}$ Institut National de la Recherche Agronomique, UR892, Virologie Immunologie Moléculaires, Domaine de Vilvert, 78350, \\ Jouy-en-Josas, France
}

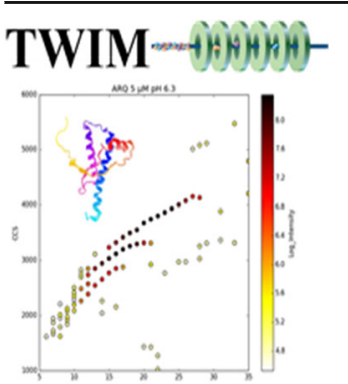

\begin{abstract}
Prion protein is involved in deadly neurodegenerative diseases. Its pathogenicity is linked to its structural conversion ( $\alpha$-helix to $\beta$-strand transition). However, recent studies suggest that prion protein can follow a plurality of conversion pathways, which hints towards different conformers that might coexist in solution. To gain insights on the plasticity of the ovine prion protein (PrP) monomer, wild type (A136, R154, Q171), mutants and deletions of ARQ were studied by traveling wave ion mobility experiments coupled to mass spectrometry. In order to perform the analysis of a large body of data sets, we designed and evaluated the performance of a processing pipeline based on Driftscope peak detection and a homemade script for automated peak assignment, annotation, and quantification on specific multiply
\end{abstract} charged protein data. Using this approach, we showed that in the gas phase, PrPs are represented by at least three conformer families differing in both charge state distribution and collisional cross-section, in agreement with the work of Hilton et al. (2010). We also showed that this plasticity is borne both by the $\mathrm{N}$ - and C-terminal domains. Effect of protein concentration, $\mathrm{pH}$ and temperature were also assessed, showing that (1) pH does not affect conformer distributions, (2) protein concentration modifies the conformational landscape of one mutant (I208M) only, and (3) heating leads to other unfolded species and to a modification of the conformer intensity ratios.

Keywords: Ion mobility, Mass spectrometry, Prion, Ovine, Plasticity, Dynamic

Received: 3 May 2016/Revised: 5 October 2016/Accepted: 6 October 2016/Published Online: 18 October 2016

\section{Introduction}

$T^{1}$ he resurgence of ion mobility in the field of mass spectrometry these last $10 \mathrm{y}$ provides an additional dimension for separation of ionized compounds in a traveling wave ion mobility (TWIMS) cell containing an inert gas (usually nitrogen) settled in a commercially available quadrupole time-offlight mass spectrometer (Synapt HDMS G2-Si; Waters Corp., Manchester, England). TWIMS experiments allow differentiating molecules according to their charge state (CS), collisional cross section (CCS, $\Omega$ ), and size with the determination of drift times (td), a parameter reflecting gas-phase conformation of

Electronic supplementary material The online version of this article (doi:10. 1007/s13361-016-1522-x) contains supplementary material, which is available to authorized users.

Correspondence to: Frédéric Halgand; e-mail: Frederic.Halgand@u-psud.fr proteins and peptides (for further details about TWIMS, see references [1] and [2]). The TWIMS cell, either alone [3] or in conjunction with hydrogen exchange [4-6], allows gaining insight, in the submillisecond time scale, on ligand-protein interactions [7]. Such a technology also allowed unveiling conformational changes upon ligand binding under noncovalent conditions [8], or revealing subtle changes between reduced and oxidized states [9], and in protein sequence [10]. By preserving protein-ligand complexes and the conformational ensemble of proteins in the gas phase, ion mobility has emerged as a powerful tool for the study of macromolecular structures [11]. However caution must be taken on data interpretation since Borysik et al. demonstrated that differences could exist between gas-phase and solution-phase protein structures [12]. Proteomic approaches also benefit from this new tool, as exemplified by studies reporting the successful characterization of glycans and the direct identification of proteins in tissue sections [13]. 
These approaches have allowed the study of protein conformations and changes of conformation occurring in solution with a view on the gas-phase changes, for instance on the Syrian prion protein $(\mathrm{PrP})$ conformers [14]. Transmissible spongiform encephalopathies are deadly neurodegenerative pathologies that affect humans and several mammal species such as sheep and cattle. The agent responsible for these pathologies is a small protein physiologically present in the major part of the animal kingdom, called the prion protein $(\operatorname{PrP})$ [15]. Prion diseases are characterized by a conformational change of the cellular form of the $\operatorname{PrP}\left(\mathrm{PrP}^{\mathrm{c}}\right)$ and the aggregation of the endogenous form leading to the formation of amyloid plaques made of insoluble fibers of pathogen $\operatorname{PrP}\left(\operatorname{PrP}^{\mathrm{Sc}}\right)$ [16]. The partial resistance of $\operatorname{PrP}^{\mathrm{Sc}}$ toward proteinase $\mathrm{K}$ in infected tissues constitutes the unique biochemical marker of prion diseases and implies the existence of different conformations between $\operatorname{PrP}^{\mathrm{c}}$ and $\mathrm{PrP}^{\mathrm{Sc}}$. More specifically, the pathologic form is related to the transition of $\alpha$-helices to $\beta$-strands [15, 16]. Pathologic forms of PrP can appear spontaneously by point mutations or $\mathrm{pH}$ change that promote protein misfolding. $\mathrm{PrP}^{\mathrm{Sc}}$ pathologic forms can transmit this misfolding by serving as a template for promoting $\alpha$-helices to $\beta$-strands transition on $\operatorname{PrP}^{\mathrm{c}}$. This constitutes the basis of the "protein only hypothesis," which claims that the pathologic form is sufficient to initiate a templating process in the absence of any other pathogen [15]. Aggregation of the $\beta$-strand conformers leads to the amyloid aggregates observed in diseased patients, although the neurotoxicity of the prion protein is thought to be rather associated to oligomer formation than to that of mature aggregates [17-19].

In this study, we focus on the sheep prion protein ( $\mathrm{PrP}$ ) (Ala 136, Arg 154, Gln 171 variant named PrP ARQ) as a model, which is the main form represented in sheep. This mildly pathogenic prion protein is a glycoprotein of 209 amino-acids bound to the cell membrane by a GPI anchor. Glycosylations are located on two asparagine residues (N181 and N197). To date, most structural information has been obtained for recombinant ovine prion proteins [20,21]. From a structural point of view, the ovine prion protein is made of a globular C-terminal domain and of an unstructured N-terminal domain (see top of Fig. 3). Helices 2 and 3 located in the C-terminal domain are linked by a disulfide bridge that rigidifies the $\mathrm{C}$-terminal domain. The $\mathrm{N}$-terminal domain contains basic amino acids that are positively charged at physiological $\mathrm{pH}$. This latter also contains some octarepeat domains, a region followed by a potentially transmembrane hydrophobic segment $[22,23]$. To better understand the molecular basis of PrP conformational switch, the structure of recombinant PrP has been obtained by $\mathrm{X}$-ray crystallography [21]. Unfortunately, little is known on the pathologic $\operatorname{PrP}\left(\mathrm{PrP}^{\mathrm{Sc}}\right)$, and proposed structures are controversial. It is noteworthy that PrP can adopt several different conformations, a characteristic that led to complications for structure determination. Molecular dynamic modeling also studied the effect of $\mathrm{pH}$ and temperature, alone or combined on the stability and dynamics of the PrP [24]. This in silico modeling demonstrated that the unfolding of $\mathrm{H} 2$ and $\mathrm{H} 3$ helices is a key event in the transition of the PrP toward its pathologic form, and leads to an increase in $7 \%$ of $\beta$-strands leading to a global structure $11 \%$ more compact [24]. In this model, $\alpha$-helices $\mathrm{H} 2$ and $\mathrm{H} 3$ could be the core of the oligomerization process [25]. This hypothesis is in disagreement with another model proposing that the S1-H1-S2 region may take an important role in nucleation and propagation of $\beta$-strand structures as well as in oligomer formation or polymerization process [22]. Recently, it was demonstrated that cytopathogenicity and infectivity are two uncoupled processes. These observations suggest that several conversion pathways of the full length PrP from sheep coexist during prion replication leading to the formation of discrete oligomers of various sizes and structures and to amyloid fibers. The three oligomerization pathways called $\mathrm{O} 1, \mathrm{O} 2$, and $\mathrm{O} 3$ for ovine ARQ lead to the formation of final products of 12, 24, and 36 mer, respectively [26]. Recently, it was shown that point mutations specifically led to O1 (K188A) or O3 (I208M/I208W) oligomer formation. All these mutations also affect the formation of amyloid fibers that in fine differ by their size and shape. All these observations suggest the existence of a strong plasticity of ovine ARQ protein and of a plurality of conversion pathways [24, 27].

In 2010, Hilton et al. studied the ion mobility properties of the Syrian prion protein C-terminal domain either under its "native" or pathologic form. Data clearly showed no or extremely small collisional cross-section difference between the physiological and pathologic form at $\mathrm{pH} 7$, whereas small differences were observed at $\mathrm{pH} 5.5$, a result in agreement with biological reports that prion proteins undergo structural changes at acidic $\mathrm{pH}$. Under these two conditions, at least three conformer families were detected, a result in agreement with arrival time distribution of selected charge states that revealed the presence of multiple conformers [14]. Considering the high plasticity of the ovine ARQ, the knowledge of in vitro conditions (buffer, $\mathrm{pH}$, temperature) leading to oligomer formation, and the availability of mutants preferentially leading to a single oligomerization pathway, we intended to extend the approach pioneered by Hilton and al. to the ovine PrP system with the aim to describe the plasticity of the initial monomer. This study also tackles the role of the unstructured N-terminal domain on full length protein in contrast with the Hilton study, which focused on the C-terminal domain.

Questions addressed in this article are the following:

1) According to the high plasticity of prion protein, is the full length protein represented by more or fewer conformer families in comparison with data obtained by Hilton et al. on the C-terminal domain [14]?

2) Similarly, is the high plasticity of the initial prion protein borne by the whole protein or by a specific domain?

3) Since oligomerization was shown to occur via different pathways, does the selection of one specific pathway by the introduction of a point mutation modify the conformational landscape of initial prion protein?

4) As PrP oligomerization can be initiated through a change in $\mathrm{pH}$ and temperature, how do changes in $\mathrm{pH}$, protein 
concentration, and $\mathrm{pH}$ affect the conformer family distributions for ARQ and three of its mutants (K188A, I208M, I208W)? This question is also relevant for the physiological process, as protein concentration and $\mathrm{pH}$ can vary upon $\mathrm{PrP}$ location in the cell.

In order to answer these questions, a large body of ion mobility data was produced, and its interpretation and comparison required the development of a processing pipeline, which is also described and discussed herein.

\section{Material and Methods}

\section{Production of PrP Proteins and Mutants}

The full length PrP from sheep (Ala 136, Arg 154, Gln 171 variant named PrP ARQ) was expressed in Escherichia coli and purified as described previously [23]. Briefly, the gene encoding for the full-length $\operatorname{PrP}$ was cloned in a pET $22 \mathrm{~b}+$ plasmid and expressed in the BL21 DE3 Escherichia coli strain after isopropyl $\beta$-D-1-thiogalactopyranoside induction (IPTG). The expressed PrP ARQ proteins accumulated in inclusion bodies. After lysis, sonication and solubilization of the inclusion bodies by a guanidinium chloride solution, purification of the prion protein was performed on a Ni Sepharose column. Refolding of the protein was achieved on the column by heterogeneous phase renaturation combined with on-column purification. The protein was recovered in the desired buffer by elution on a G25 desalting column. Mutants (K188A, I208M, and $\mathrm{I} 208 \mathrm{~W}$ ) as well as $\mathrm{N}$-terminal and C-terminal constructs and $\Delta$ 103-124 mutant were prepared by introducing the point mutation at the desired position or specific plasmid for construct and expressed and purified as for the PrP ARQ protein.

\section{Mass Spectrometry Analyses}

Mass spectrometry experiments were performed on a QToF instrument (Synapt G2-Si HDMS; Waters, Manchester, UK) equipped with a traveling wave ion mobility cell. All samples were infused using the nanoflow ion source at a $1 \mu \mathrm{L} / \mathrm{min}$ flow rate and analyzed in the positive ion mode. Acquisition of mass spectra was carried out over the 500 to $5000 \mathrm{~m} / \mathrm{z}$ mass range and $\mathrm{m} / \mathrm{z}$ calibration was performed using sodium trifluoroacetate leading to a typical error below $10 \mathrm{ppm}$. For analysis under denaturing solution conditions, experimental parameters set on the instrument were: capillary voltage $=3.0$ $\mathrm{kV}$, sampling cone $=55 \mathrm{~V}$, source offset, $30 \mathrm{~V}$, nanoflow gas pressure $=0.5 \mathrm{bar}$, source temperature, $80{ }^{\circ} \mathrm{C}$. For nondenaturing analyses, experimental parameters were: capillary voltage $=3.5 \mathrm{kV}$, sampling cone $=95 \mathrm{~V}$, source offset $=90$ $\mathrm{V}$, nanoflow gas pressure $=0.5 \mathrm{bar}$, source temperature $=120$ or $40^{\circ} \mathrm{C}$. Source temperature in nondenaturing solution condition was increased to help desolvation. However, we carefully checked that source temperature did not promote any structural denaturation by recording the same spectrum at $40^{\circ} \mathrm{C}$. Under this last condition, spectra were found identical at both $40{ }^{\circ} \mathrm{C}$ and $120^{\circ} \mathrm{C}$ source temperature, respectively (see Figure 1 of Supplementary material). For ion mobility experiments, instrumental parameters were the following: drift gas was nitrogen, and T-wave parameters were: trap gas flow $=2 \mathrm{~mL} / \mathrm{min}$; IMS gas flow $=90 \mathrm{~mL} / \mathrm{min}$, trap wave velocity $=300 \mathrm{~m} / \mathrm{s}$, trap wave height $=4 \mathrm{~V}$, He cell gas flow $=180 \mathrm{~mL} / \mathrm{min}$, IMS wave velocity $=950 \mathrm{~m} / \mathrm{s}$, IMS wave height $=40 \mathrm{~V}$, transfer wave velocity $=175 \mathrm{~m} / \mathrm{s}$, and transfer wave height $=4 \mathrm{~V}$.

\section{Sample Preparation for Mass Spectrometry}

For standard analyses (denaturing conditions) samples were prepared at a final concentration of $1 \mu \mathrm{M}$ using a mixture of $50 \%$ acetonitrile containing $0.1 \%$ formic acid. Under nondenaturing conditions, samples were prepared in $5 \mathrm{mM}$ ammonium acetate at a final concentration of $0.5,1,5$, and $10 \mu \mathrm{M}$ and for two $\mathrm{pH}$ values of 6.3 or 3.1. PrP stock solutions were prepared by weighing a few mg (typically between 2 and $4 \mathrm{mg}$ ) of each protein that was then dissolved in $200 \mu \mathrm{L}$ of water. Absorbance at $280 \mathrm{~nm}$ was then recorded and concentration calculated according to Beer Lambert's law taking into account a molar extinction coefficient for PrP of $575981 . \mathrm{mol}^{-1} \cdot \mathrm{cm}^{-1}$.

\section{Cross-Section Calibration of the Ion Mobilities}

Since it was shown by the seminal work of Shvartsburg and Smith [28] that the drift time in TWIMS cannot be directly correlated to absolute collisional cross-sections, we processed data according to the protocol referring to $\operatorname{CCS}(\Omega)$ calibration in TWIMS defined by Ruotolo et al. [29] in order to obtain an estimate of the absolute collisional cross section. To calibrate CCS denatured myoglobin was used since the charge state distribution (CSD) of this latter globally covers the CSD of the PrP and that both proteins have roughly similar masses (16.9 kDa for myoglobin and $23 \mathrm{kDa}$ for PrP). This calibration was performed with mobility parameters strictly identical to those used for measuring PrP. It should be pointed out that this calibration procedure is only meant to give an estimate of the absolute cross-section values, since we are aware that the reference values only partially cover those measured on our system and that we had to resort to using a denatured protein and not a native protein. Then $\Omega=\mathrm{f}(\mathrm{z})$ was plotted for all protein and all experimental conditions and used to describe our data.

\section{Ion Mobility Data Processing}

Data analysis of ion mobility experiments was performed as follows. First, ion mobility spectra were opened in the Driftscope software. Then we performed a peak detection using a resolution of 2000 and a signal threshold detection of 2000 counts. At this stage, an Apex3D ion file (.csv) is created. A home-made Python/Matplotlib/PyQt program allows the extraction of data from the CSV file $(\mathrm{m} / \mathrm{z}$, intensities, drift time), selects data points that belong to a charge state of the protein under study, performs CCS calibration using the procedure and 
parameters described in the previous section, and plots the CCS as a function of charge state with intensities indicated by a color map. This program allows data manipulation (assignment to conformer families, calculation of total and relative intensities, ...) and interaction with the plotted data. All the graphs presented in this article as well as most combined data were produced using this program, which is freely accessible on request to the authors.

\section{Results and Discussion}

\section{Data Processing and Interpretation}

First authenticity and purity of PrPs were determined by recording their mass spectra under denaturing conditions. These experiments allowed assessing the correct expression and the good purity of all PrPs as well as the presence of an oxidation of the disulfide bond linking $\alpha$-helices H2 and H3. The mass spectra of the PrPs were then recorded under "nondenaturing" solution conditions. CSD were similar to those observed in denaturing condition. This result was attributed to the relatively unfolded nature of the $\operatorname{PrPs}$ [36]. All prion proteins were shown to be represented by a CSD spanning +12 to +33 , in average (an illustration is given in Fig. 1a for I208M mutant). After recording the ion mobility data, we specifically extracted ion mobility data of the protein under study following the procedure described in the Material and Methods section. Our script automatically computes CCS values with user provided parameters ( $X, a, b$, and $C$ factors, mass of the drift gas). $\Omega=\mathrm{f}(\mathrm{z})$ graphs are plotted with this script using a color scale on points to reflect absolute intensities. This is exemplified on Fig. 1b. This led to efficient processing of the data. One should mention here that it is possible that the responses vary for the different conformational ensembles. Hence, what is reported in Figures (signal relative abundances) could not necessarily reflect the molar fractions in solution. However, when looking at changes in abundances between different conditions, or between CSD, these should be representative of changes occurring in solution. Calibration of TWIMS-based systems to provide absolute collision cross-section for proteins is still an issue [30-32] and this article does not aim to resolve it. Since no external data is available that would actually require absolute collisional cross-section determination, the focus of this article is mostly on the changes observed in the measured collisional cross-sections.

As stated above, an example of $\Omega=\mathrm{f}(\mathrm{z})$ graphs is given for I208M mutant (Fig. 1b). In this plot, one can clearly observe series of points that we will denote as conformer families. In this denomination, we intend to convey that a single solution-phase conformation is expected to lead to a gas-phase charge state distribution (CSD) with CCS that should be closely related, and with a progression in CCS related to an increase in volume due to increased coulombic repulsion as charge states increase (see for instance [33]). This term is not totally accurate because several conformations might be present in a single conformer family. Thus, I208M mutant is represented by three main conformer families (G1, G2, (a)

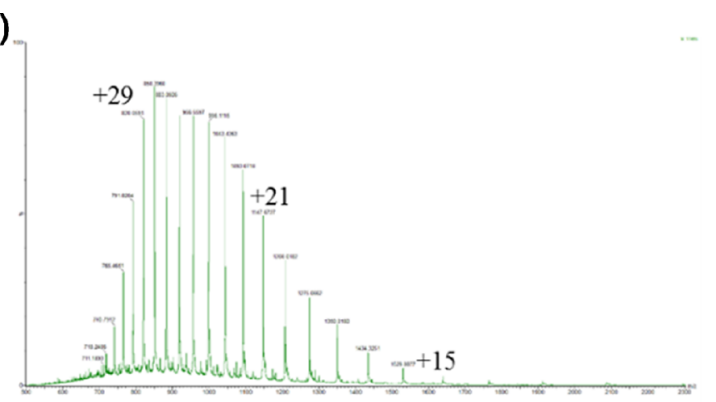

(b)

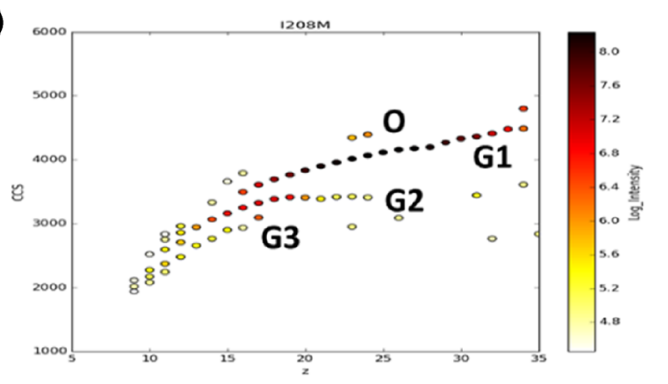

(c)

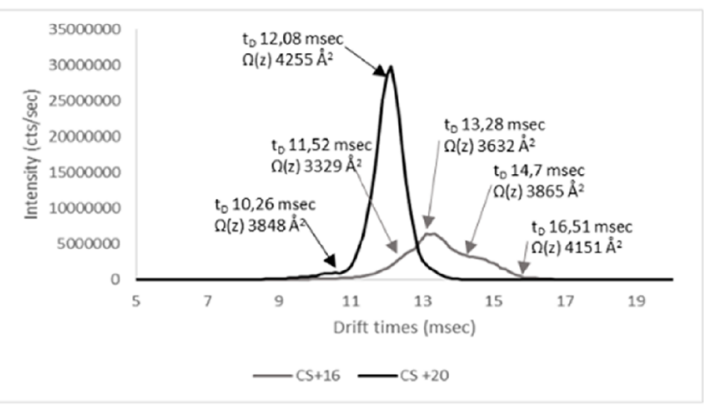

(d)

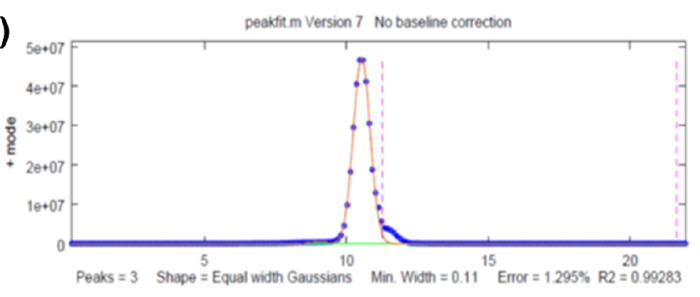

(e)

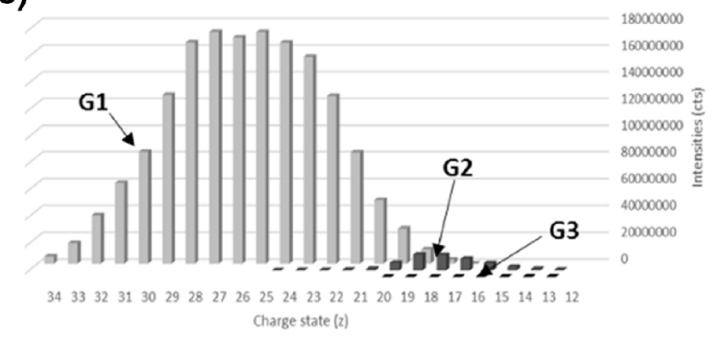

Figure 1. (a) Mass spectrum of the I208M mutant recorded under nondenaturing condition. (b) Plot of the $\Omega(z)$ versus $z$ values for I208M mutant. Conformer families are labeled with brackets and numbered from 0 to 3. (c) Extracted arrival time distributions for +20 (black trace) and +16 (grey trace) charge states of I208M mutant, showing shoulders indicating the presence of satellite conformers. (d) Data and peak profile simulation using an equal width Gaussian fit for CS +23 of I208M mutant. (e) Plot of the intensities as a function of charge state for conformer families G1, G2, and G3 
G3). Characteristics of these conformer families are given in Table 1 . An additional family is also observed (family 0 ) with only two charge states. This narrow CSD and low abundance conformer will further be shown to be modified by the concentration and/or the thermal treatment of the monomer. Observation of Fig. $1 \mathrm{~b}$ also shows that some families present different evolution of $\Omega(z)$ values as one progresses through the charge states such that variations of $\Omega(\mathrm{z})$ values could reflect other finer structural changes that might occur within a general family. These plots also showed that PrPs encompass more than one family of structures that coexist in the gas phase. This latter point was confirmed by analysis of arrival time distribution of selected CS using MassLynx software (see Fig. 1c) with the observation of shoulders either for lower or higher drift time values reflecting the presence of additional discrete conformers. As charge state distributions are often used as an indicator of the folded nature of a protein [37], the plots shed light on the overall folding modulation and conformational landscape as observed by mobility and ESI ionization. One should, however, point out that this measurement is performed in the gas phase and that solution structures might not be reflected in gas-phase conformations as structural rearrangement can occur upon ESI process. This is exemplified by the work of Borysik et al. that showed conformational expansion, collapse, and rearrangements occurring in conformational families [12]. However, if such phenomena exist in each conformer family, it is noteworthy that the ESI-MS process allowed sampling at least three different structures, which are distinct from each other by their CSDs, the $\Omega$ values, evolutions, and behavior in terms of structural changes.

The occurrence of different structures is also observed with broad arrival time distributions on some of the charge states. Thus, an interrogation remains: since our data relies on the Driftscope and its ApeX3D peak detection software, is the detection of peaks that are not baseline resolved accurate? Thus, we attempted to check how reliable the detection, annotation, and quantification of the peaks was when mobility profiles contain satellite peaks. To this purpose, we compared the peak fitting procedure of Driftscope, which processes peaks in a three dimension space (drift time, $m / z$, intensities) with a more standard Gaussian fitting of a two-dimension (drift time, intensity) extracted ion drift plot [34]. For two selected charge states of the I208M mutant (13+ and 23+) an extracted drift plot encompassing, the entire mass peak width was extracted using MassLynx, exported as CSV file, loaded in GNU Octave, and processed with the peakfit.m module (https://terpconnect.umd. edu/ toh/spectrum/peakfit.m). The fitting parameters were as follows: equal width Gaussians and 1000 randomized initial conditions for optimizations. The procedure was repeated three times in order to check that it converged to the same results on every attempt. The number of Gaussians was increased up to the threshold where the system converged to aberrant (out of bound peak center, zero, or negative intensity values, peak width obviously too low), and/or differing optimized parameters between the three replicates. In fact, the criteria of aberrant values proved sufficient, as differing values were only observed in conjunction with aberrant values. In both instances, this procedure led to the same peak position and peak height as those provided by the Driftscope extraction (Fig. 1d). Peak width was determined at $1.7 \mathrm{~ms}$ for the $13+$ charge state and $0.7 \mathrm{~ms}$ for the $23+$ charge state, which is also in good agreement with peak widths observed for single conformation proteins such as myoglobin. Thus, the results provided by the Driftscope extraction seem to be as reliable as an equal width Gaussian fitting. Processing of the ion mobility data and, more specifically, automated data extraction for specific charge states with our program allowed detecting low intensity conformer families that are hardly accessible when manually extracted in the Driftscope software.

In order to further compare conformer families, their relative intensities were calculated by summing the raw intensities (counts) of the various charge states of each conformer family. From these calculations, it appears that relative intensities of the conformer families could differ by $30 \%$ (especially on low intensity families) from one experiment to another. Consequently, we considered this parameter with caution. High diversity in intensity of the different conformer families is shown in Fig. 1e. As we can observe in this plot, the G1 conformer is the most intense family, G2 is quite low in intensity, and G3 is really weak, with calculated relative percentages of G1, G2, and G3 families of 63, 28 and 8\%, respectively. Such values correspond to a single experiment whereas other values given in the text result from the average of three experiments.

In order to define how significant changes observed in $\Omega(z)$ values are, the reproducibility of the experiments was assessed and an evaluation of error was performed. To that purpose, mobility experiments were repeated three times on denatured myoglobin used for calibration and 16 times for PrP ARQ. For calibration reproducibility, it appears from our experiments that factor $X$ calculation was reproducible with an averaged value of 0.602325 and a standard error $(\sigma)$ of 0.016 . From the average $\Omega(\mathrm{z})$ values calculated for the same CS along the 16 experiments or $\Omega(z)$ values calculated for all CS along each conformer family for the 16 experiments, the standard deviation on

Table 1. Display of CSD and $Z_{(\text {av) }}$ Values of Each Conformer Family for Each PrP

\begin{tabular}{|c|c|c|c|c|c|c|c|c|}
\hline \multirow[t]{2}{*}{ Conformer family } & \multicolumn{2}{|l|}{ ARQ } & \multicolumn{2}{|l|}{ K188A } & \multicolumn{2}{|l|}{$\mathrm{I} 208 \mathrm{M}$} & \multicolumn{2}{|l|}{$\mathrm{I} 208 \mathrm{~W}$} \\
\hline & $\mathrm{CCS}_{(\mathrm{av})} \AA^{2}$ & $Z_{\text {(av) }}$ & $\mathrm{CCS}_{(\mathrm{av})} \AA^{2}$ & $Z_{(a v)}$ & $\mathrm{CCS}_{(\mathrm{av})} \AA^{2}$ & $Z_{(a v)}$ & $\mathrm{CCS}_{(\mathrm{av})} \AA^{2}$ & $\mathrm{Z}_{\text {(av) }}$ \\
\hline 0 , & & & & & 4374 & 23.4 & & \\
\hline $1 / \mathrm{G} 1$ & 2950 & 20.8 & 4045 & 25.03 & 4071 & 24.7 & 3584 & 25.17 \\
\hline $2 / \mathrm{G} 2$ & 2728 & 17.6 & 3226 & 18.1 & 3266 & 20.32 & 2895 & 17.6 \\
\hline $3 / \mathrm{G} 3$ & 2619 & 14.85 & 3077 & 15.67 & 2624 & 15.05 & 2362 & 17.8 \\
\hline
\end{tabular}


these two values showed strong reproducibility with a standard deviation $(\sigma)$ of $11.31 \AA^{2}$. This means that differences of more than $12 \AA^{2}$ for a specific CS that belong to different conformer families should be considered significant.

\section{Comparison of Mobility Properties of All PrPs}

Figure 2 depicts the evolution of $\Omega(\mathrm{z})$ values with the charge states (z) for each PrP (native ARQ and three mutants) under nondenaturing solution condition. First, we can notice that the general picture is similar for both ARQ and the three mutants with the detection of three conformer families with a similar trend, which can probably be grouped (Group G3: low charge states distribution and low $\Omega$; Group G2: median CS and median $\Omega$; Group G1: large charge state distribution and high $\Omega$ ). This reflects the high plasticity of the PrPs. This result is in agreement with data obtained by Hilton et al [14] suggesting that multiple conformers could coexist with respect to the large spreading of the arrival time distribution observed by this group. Within this global similarity, the second observation is

(a)

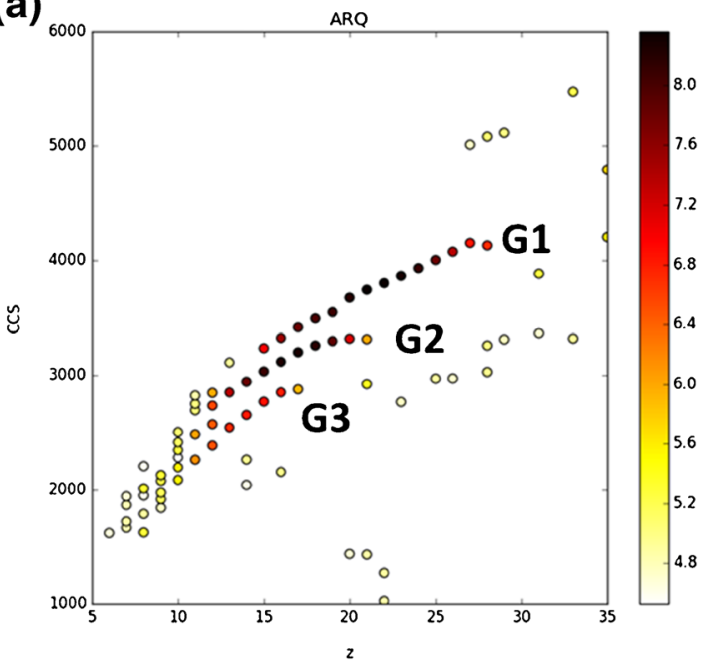

(c)

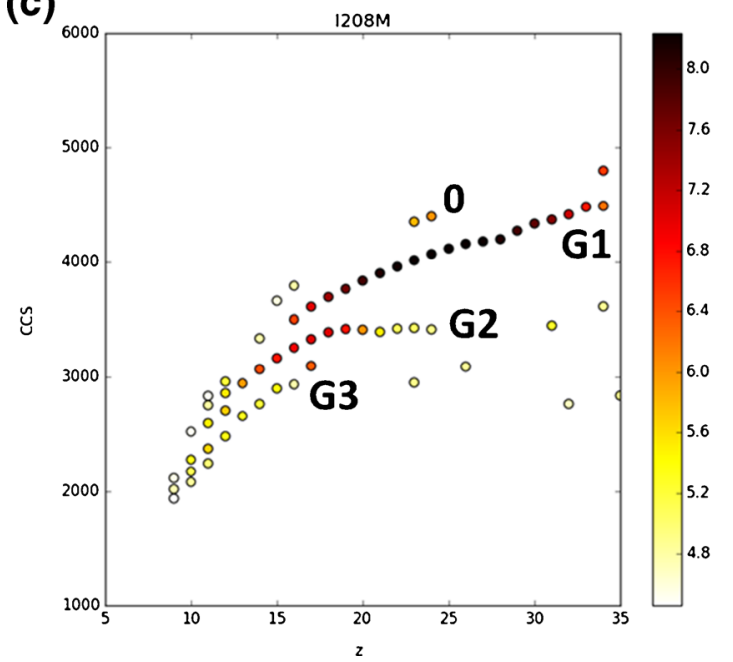

that PrP ARQ displays a slightly more compact structure than PrP mutants. This is illustrated with the determination of a mean increase in CCS for conformer family 1 and the three mutants of about $2.85 \%$ calculated for +20 to $+28 \mathrm{CS}$ and with a $\sigma$ value of 1.11 compared with ARQ. This opening of the structure in the mutants is further supported by a CSD distribution reaching higher charge states (up to $z=34$ ) compared with native ARQ. One distinction should be made for conformer family 1 of the mutants. We observed that from CS $+26 \Omega(z)$ values slightly decreased in mutants, a phenomenon that could be related to subtle conformational changes linked to charge repulsion. Such observation is also true for the highest charge states of conformer families 2 and 3 . In addition we determined a mean increase in CCS for conformer family 2 and the three mutants of about $3.81 \%$ calculated for +12 to $+17 \mathrm{CS}$ with a $\sigma$ value of 0.36 compared with ARQ (see Table 1 reporting CSD and $\mathrm{Z}_{(\mathrm{av})}$ values and classification of conformer families into groups). An initial question is: how reasonable is it to assign and compare CCS and charge state data between proteins that are different? First, it should be pointed out that the overall

(b)

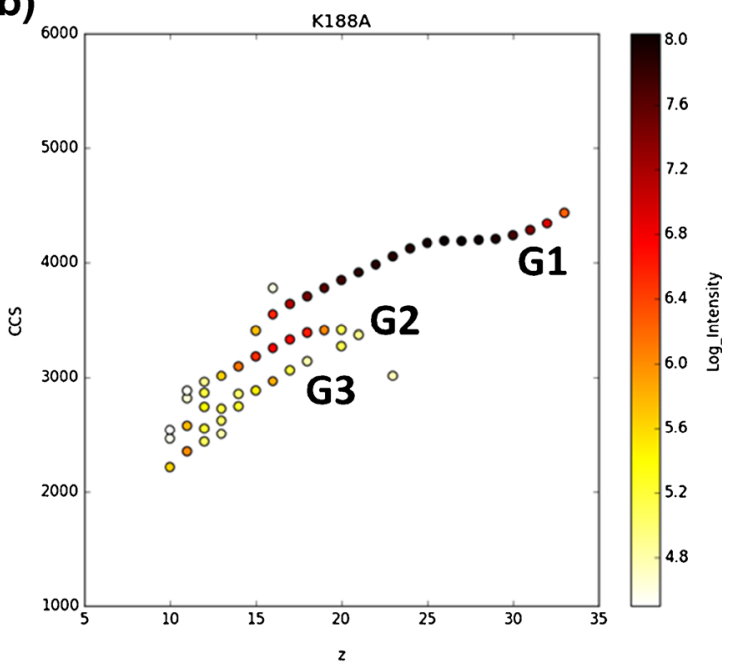

(d)

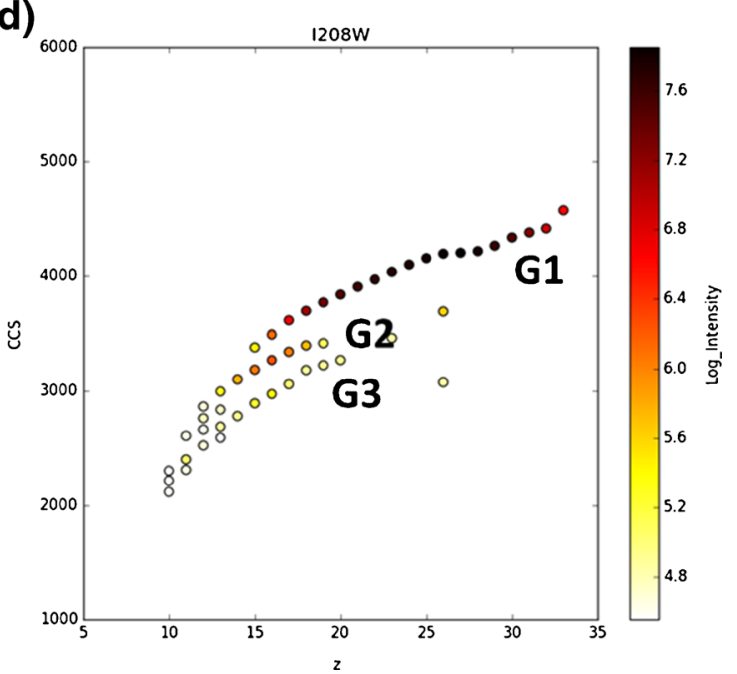

Figure 2. $\Omega(z)$ plots for PrP ARQ (a); K188A (b); I208M (c), and I208W (d). Conformer families for each PrP are numbered. PrP concentration was $5 \mu \mathrm{M}$ and $\mathrm{pH}$ was 6.3. Grouping of similar conformer families across all protein is labeled $\mathrm{G} 1$ to $\mathrm{G} 3$ 
effect of point mutation on size is probably negligible. To check this assumption, we compared CCS for +17 CS for all PrPs and the three conformer families. It appears that conformers 2 and 3 have smaller CCS that differ by an average of $-6 \%$ and $-14 \%$ compared with conformer 1 . As these variations are similar for all four proteins, it is likely that they point towards similar changes in the overall protein structure and that we can thus consider the conformer families throughout the three mutants and the wild type protein. In all four instances, the main conformer family represents around 50 to $70 \%$ of the total ions, and the minor conformer families' relative intensities range between 5 and $20 \%$. Comparison of the intensities between mutants was not deemed reliable since significant errors were reported from one experiment to another. Another question arising at this stage is to determine whether one or several conformer families could be related to a specific pathway of oligomerization. According to our results, mutants that specifically lead to the production of O1 (I208W and $\mathrm{K} 188 \mathrm{~A}$ ) or O3 (I208M) oligomers all displayed similar conformational landscapes represented by at least three conformer families. This means that under our experimental conditions we did not observe the unfolding intermediate(s) that could be directly related to the formation of specific oligomers.

\section{Comparison of Mobility Properties of ARQ PrPs Constructs}

A surprising point in the previous results was that although our experiments were performed on the full ovine PrP protein compared with the C-domain restricted Syrian prion protein described by Hilton et al. [14], three conformation families were still observed as in the previous work. It was thus of interest to evaluate the regions involved in the conformational plasticity in the case of the ovine protein, in order to check if the three conformer families observed in this work are similar in origin to those of the $\mathrm{C}$-terminal domain, or if differing species explain these results. Thus, the following constructs, ARQ N-ter (AA 23103; $9960 \mathrm{Da}$ ), ARQ C-ter (AA 124-234, 16167.7 Da), and ARQ

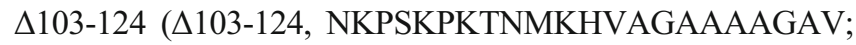
20784.8 Da) were analyzed by ion mobility (Fig. 3, upper panel). First, ARQ N-ter (see Fig. 3b), which encompasses roughly the $\mathrm{N}$-terminal half of the protein, is represented by at least two conformer families. Although direct comparison of the CSD and the CCS is not possible, one can still observe that the CSD for both conformer families cover three to five charge states, more like structured gas-phase proteins compared with the wide CSDs observed for denatured or unstructured proteins. Second, ARQ C-ter was shown to display two or three conformer families (see Fig. 3c). Third, ARQ $\Delta 103-124$, which corresponds to the deletion of the basic and hydrophobic region in PrP linking the Nand C-terminal domain, presents the highest plasticity with the detection of at least four conformer families (see Fig. 3d). Thus, ARQ N-ter seems to possess a low flexibility and an ordered structure. In contrast, ARQ C-ter, with its wide CSD observed upon desolvation, has some propensity towards an unordered structure, and this occurs in spite of the presence of the disulfide bridge linking $\alpha$-helices $\mathrm{H} 2 / \mathrm{H} 3$, which would usually be thought to lead to a compact and structured region. Finally, deletion of the hydrophobic region leads to reduction in charge state distribution width towards lower charge states but globally does not affect conformer family profiles, which were found similar to those of ARQ. Comparison between constructs is a difficult attempt as the change in protein size and number of protonation sites lead to a strong change in CCS as well as CSD. Nevertheless, one can observe that the N-terminal construct does not present an extended CSD usually associated with unfolded structures, whereas the C-terminal construct presents a high intensity low CSD conformer family and two low intensity high CSD conformer families (Fig. 3). Full length ARQ is represented by two low intensity low CSD conformer families and a high intensity high CSD conformer family. Evolution towards this high intensity large CCS and high CSD conformer family thus requires both the presence of the $\mathrm{N}$-ter and $\mathrm{C}$-ter domains, although one should point out that the C-ter domain already displays a latent, low abundance, large CCS and high CSD conformer family. In the absence of the hydrophobic region linking $\mathrm{N}$-ter and $\mathrm{C}$-ter domains, the number of conformer families is increased; thus, this region is necessary to direct the protein structure towards a reduced number of conformer families. Taken together, these results suggest a conformation interaction network [35] between the $\mathrm{N}$ - and C-terminal domains that is probably mediated/modulated by the hydrophobic 103124 region. On the one hand, the presence of strongly basic amino acids on the 103-124 region (four lysine and one histidine residues), could favor the presence of charges in this hinge region, which could lead to unfolding in the ESI process. On the other hand, the increase in number of conformational families when both domains are bound without this intermediate link indicates that it plays a role in plasticity of PrP by reducing the extent of movements for this construct, probably through hydrophobic or charge mediated interactions with both $\mathrm{N}$ - and $\mathrm{C}$-terminal domains.

\section{Effect of Protein Concentration and $\mathrm{pH}$}

Prion protein is prone to undergo concentration changes depending on its location in cells. In this context, concentration effect upon mobility properties of the prion protein was analyzed. In order to assess the effect of protein concentration upon mobility properties of PrPs, one should keep in mind that changes in concentration will affect signal to noise ratio and intensities of peaks used to determine the mobility of each CS and the calculation of the $\Omega$ values. Under these conditions, we considered that significant $(3 \sigma)$ variations of at least $36 \AA^{2}$ should be used as a criterion. No major effect of protein concentrations from 0.5 to $10 \mu \mathrm{M}$, and for higher concentrations of 50 and $80 \mu \mathrm{M}$ (data not shown), upon mobility properties was observed for all PrPs (see example of K188A mutant in Fig. 2 of Supplementary Material), except for the I208M mutant (Fig. 4). In this latter case, an extra (0), high CCS conformer family appears at the lowest protein concentrations $(0.5 \mu \mathrm{M}, \mathrm{pH}$ 3.1) and decreases as protein concentration 


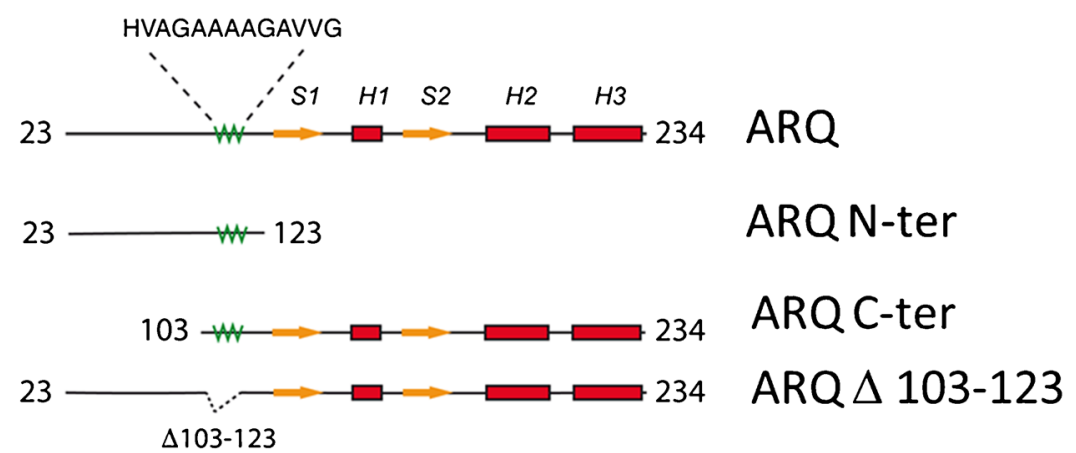

(a)

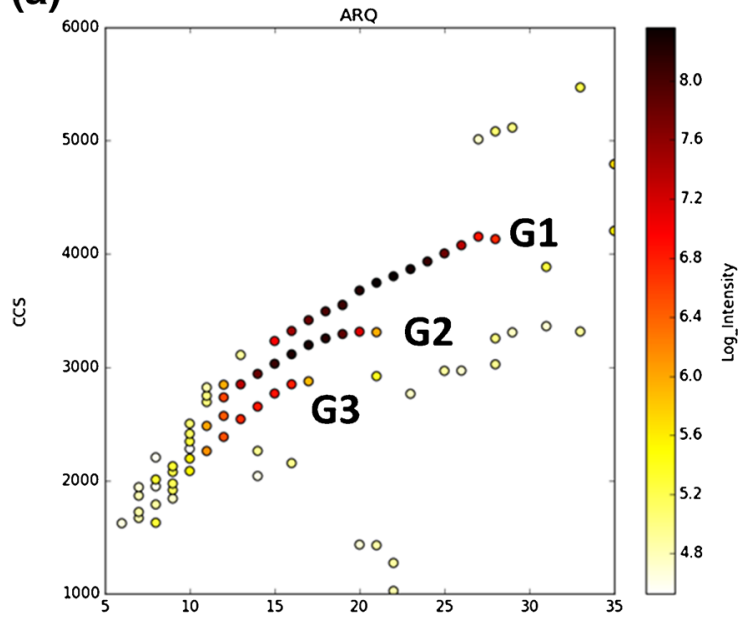

(c)

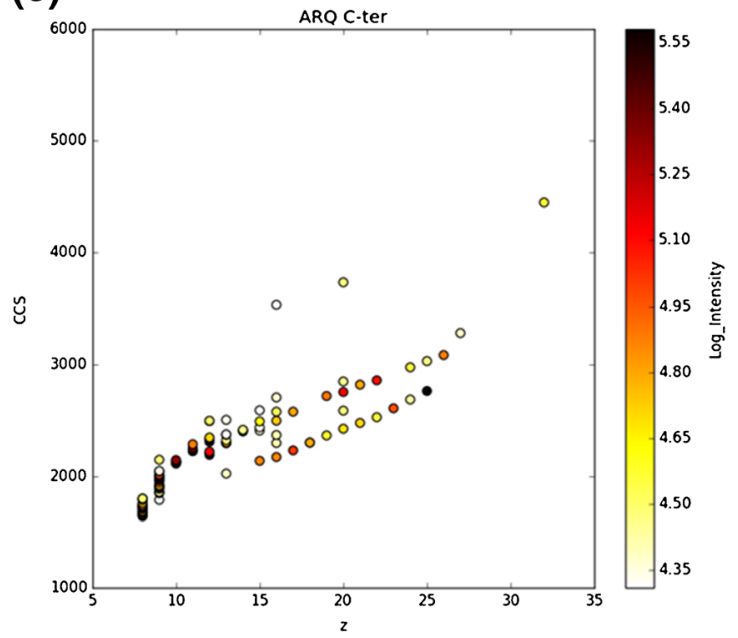

(b)

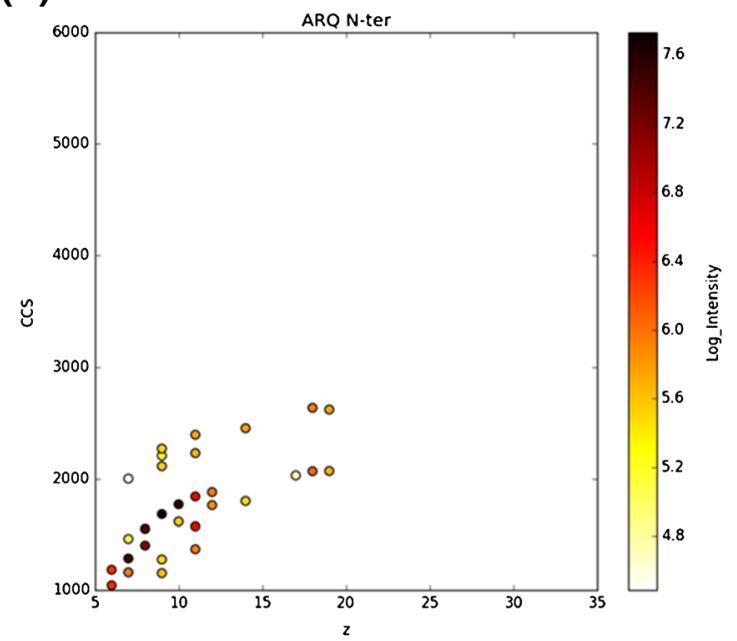

(d)

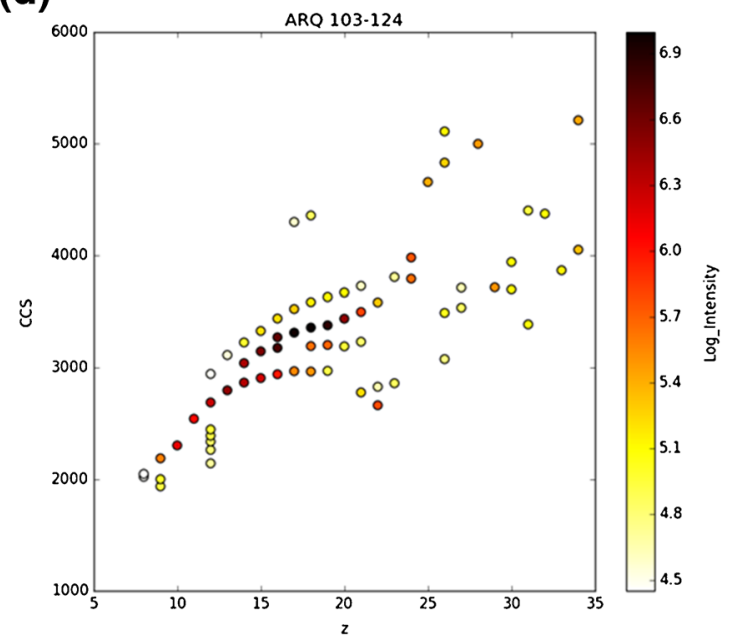

Figure 3. $\Omega(z)$ plots for full length PrP ARQ (a), ARQ N-ter (23-103) (b), ARQ C-ter (124-234) (c), and ARQ $\triangle 103-124$ (d) showing the mobility profiles of these PrP constructs at $\mathrm{pH} 6.3$ and a protein concentration of $5 \mu \mathrm{M}$. A scheme of the constructs is given in the upper panel

increases. Then the effect of protein concentration was checked for I208M at pH 6.3 (see Fig. 3 of Supplementary Material). In this latter case conformation family 0 remains weak at all protein concentrations. Consequently, the appearance of an additional conformer family at the lowest concentrations that disappears at larger concentrations is an indication that the dynamics of the I208M conformation could be influenced by the presence of other molecules of PrP in solution. This would be an indication that some interaction between monomeric PrP (transient or long-term) occurs in solution. Two possible origins of these protein interactions could be (1) a "templating" behavior in which interaction of conformer family 0 monomer with another more folded monomer would refold it, or (2) formation of higher order structures (dimer, O3 12-mer or even insoluble fibrils), which were not measured in our experiments. 
(a)

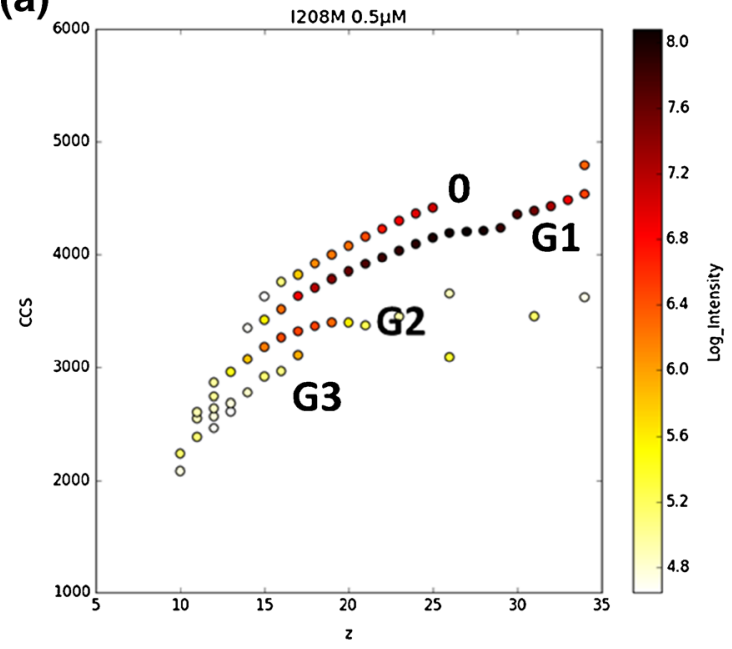

(c)

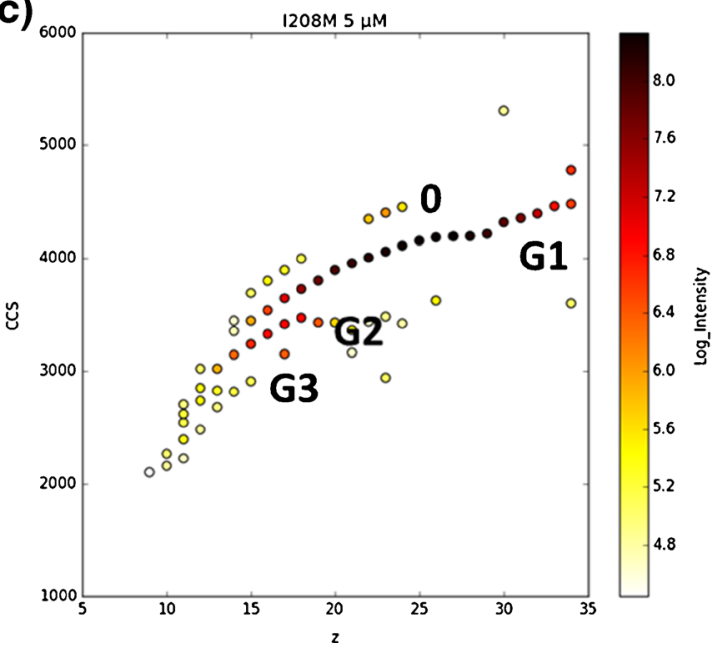

(b)

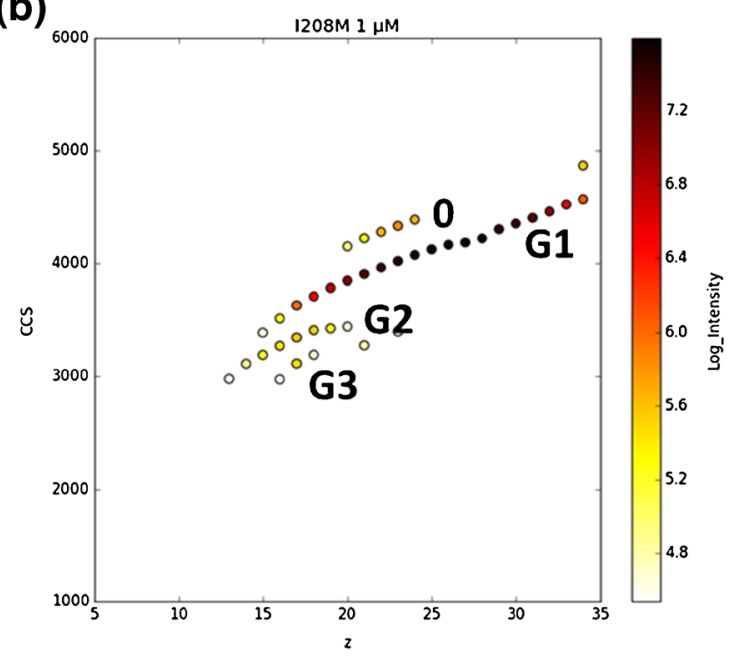

(d)

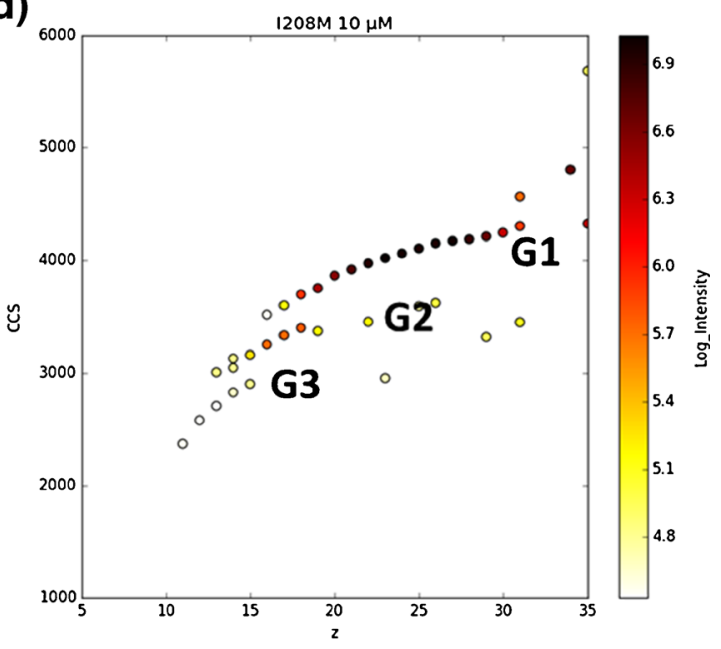

Figure 4. $\Omega(z)$ plots for I208M PrP mutant at increasing concentrations (a) $0.5 \mu \mathrm{M}$; (b) $1 \mu \mathrm{M}$; (c) $5 \mu \mathrm{M}$, and (d) $10 \mu \mathrm{M}$ at pH 3.1 . Conformer families for each PrP are numbered. Grouping of similar conformer families across all protein is labeled G1 to G3

Since prion protein experiences different $\mathrm{pH}$ with regards to its location in the cell, we considered the effect of $\mathrm{pH}$ by recording ion mobility properties of all PrPs for a protein concentration of $5 \mu \mathrm{M}$ at $\mathrm{pH} 3.1$ and 6.3 (see Figure 4 of Supplementary Material). As observed in the mobility diagrams, results are similar at both $\mathrm{pH} 6.3$ and $\mathrm{pH} 3.1$ for the three variants ARQ, I208M, and K188A. Globally it appears that change of $\mathrm{pH}$ has no effect or very weak effect upon PrP structures. A small effect of $\mathrm{pH}$ is observed for the K188A mutant, for conformer family G1 structures from the charge states +23 to +27 for which a small increase in CCS is observed at $\mathrm{pH} 6.3$ compared with $\mathrm{pH}$ 3.1. One should mention here that observation of a similar mobility pattern does not imply that structures are identical.

If $\mathrm{pH}$ does not seem to alter the conformational pattern, protein concentration was shown to promote changes for I208M mutant with the appearance of low abundant new conformer family at the lowest conformations. Such result could be related to the effect of mutation that specifically led to the production of $\mathrm{O} 3$ oligomer. In other words, this result could suggest that conformational family 0 might play a role in the formation of specific species at a low protein concentration that could evolve toward $\mathrm{O} 3$ oligomers. This hypothesis is under investigation in our laboratory. These results suggest that plasticity and structure of the mutant PrPs are globally not affected in vitro by $\mathrm{pH}$ or protein concentration variations, except for the I208M mutant.

\section{Effect of Temperature}

Although $\operatorname{PrP}^{\mathrm{c}}$ has been widely studied, $\operatorname{PrP}^{\mathrm{Sc}}$ is still poorly characterized and the molecular determinants responsible for the conversion process of $\operatorname{PrP}^{\mathrm{c}}$ to $\operatorname{PrP}^{\mathrm{Sc}}$ remain poorly described. In this context, we explored the dynamic of the "heated native" $\operatorname{PrP}$ monomer. $\mathrm{PrP}^{\mathrm{c}}$ was heated at low and high concentrations in ammonium acetate to promote structural conversion. The effect of temperature on $\mathrm{PrP}$ conformations was assessed by heating the proteins either at $\mathrm{pH} 3.1$ for a concentration of 10 or $50 \mu \mathrm{M}$, or at $\mathrm{pH} 6.3$ for a concentration of 10 or $80 \mu \mathrm{M}$ in ammonium acetate for $2 \mathrm{~h}$ at $70{ }^{\circ} \mathrm{C}$, diluted to $5 \mu \mathrm{M}$ in the same $\mathrm{pH}$ ammonium acetate buffer, and injected directly 
into the mass spectrometer. The goal was to detect a possible existence of new conformers of PrP upon thermal unfolding in acetate ammonium. This buffer does not lead to the formation of oligomers: oligomer formation is achieved by thermal

(a)

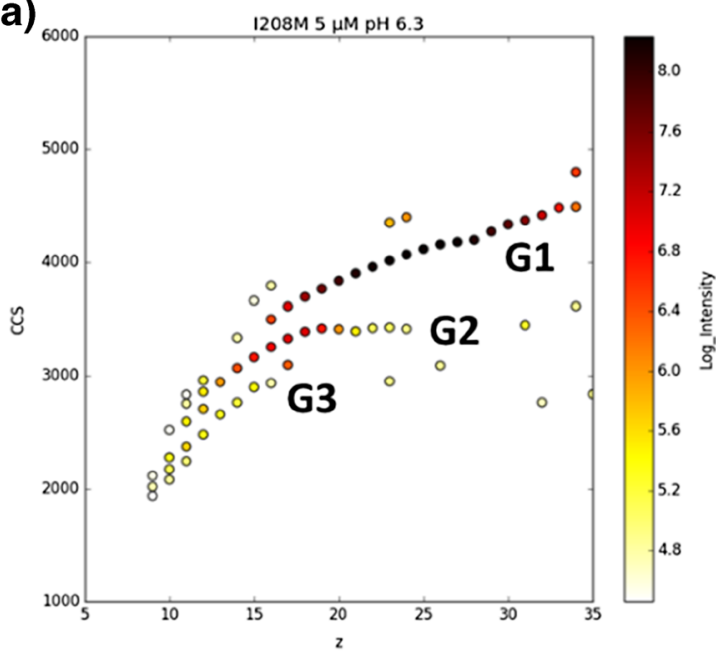

(b)

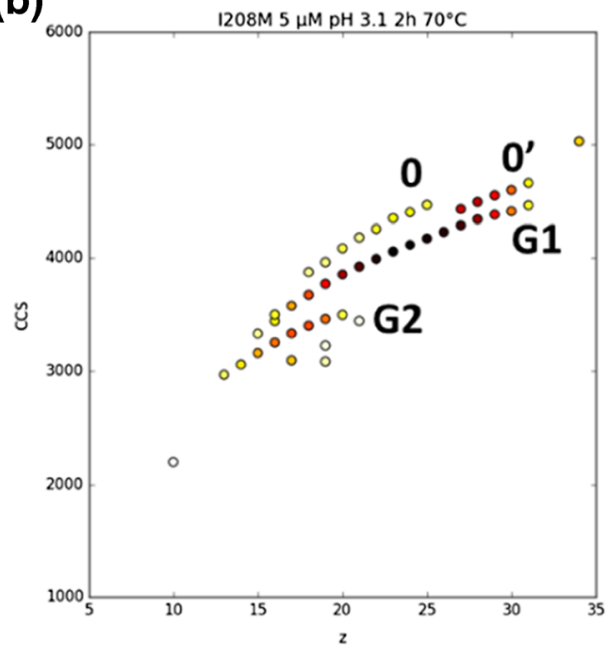

(c)

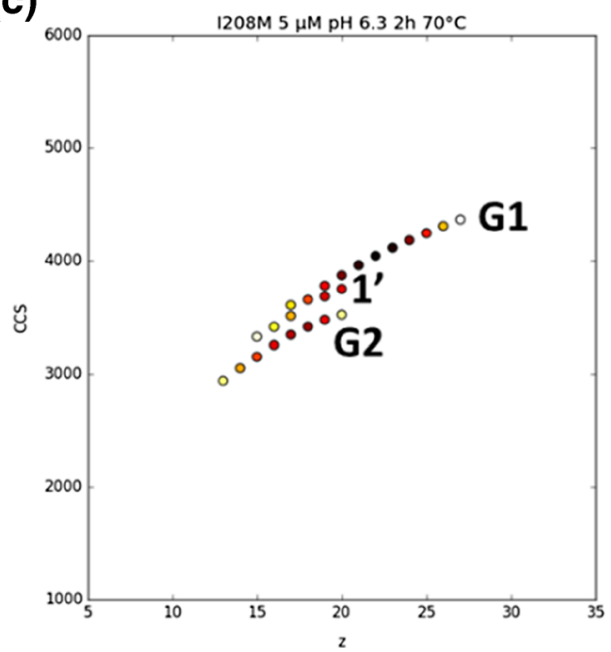

unfolding for $2 \mathrm{~h}$ at $50{ }^{\circ} \mathrm{C}$ to $65{ }^{\circ} \mathrm{C}$ in sodium citrate at $\mathrm{pH}$ 3.35 [22]. Mobility data were recorded and compared with those obtained at room temperature. From these experiments, it appears that significant differences are observed in mobility (d)

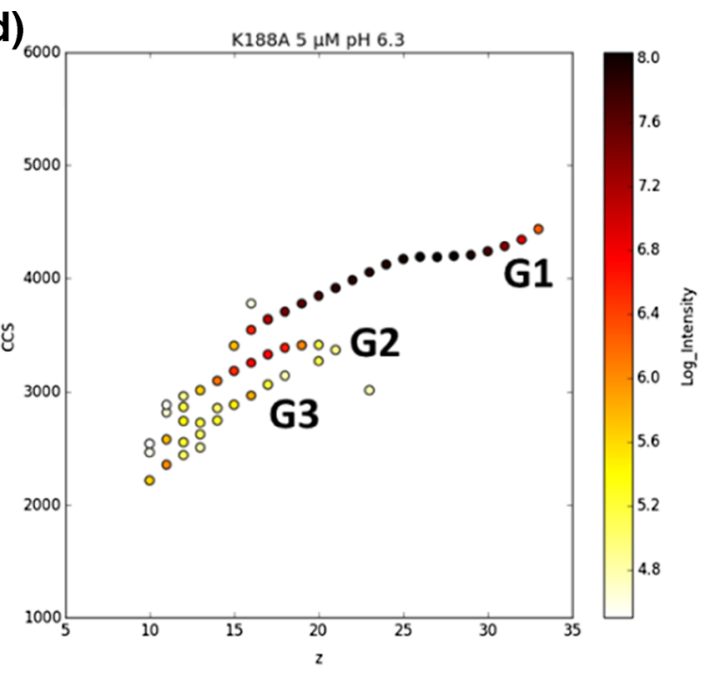

(e)
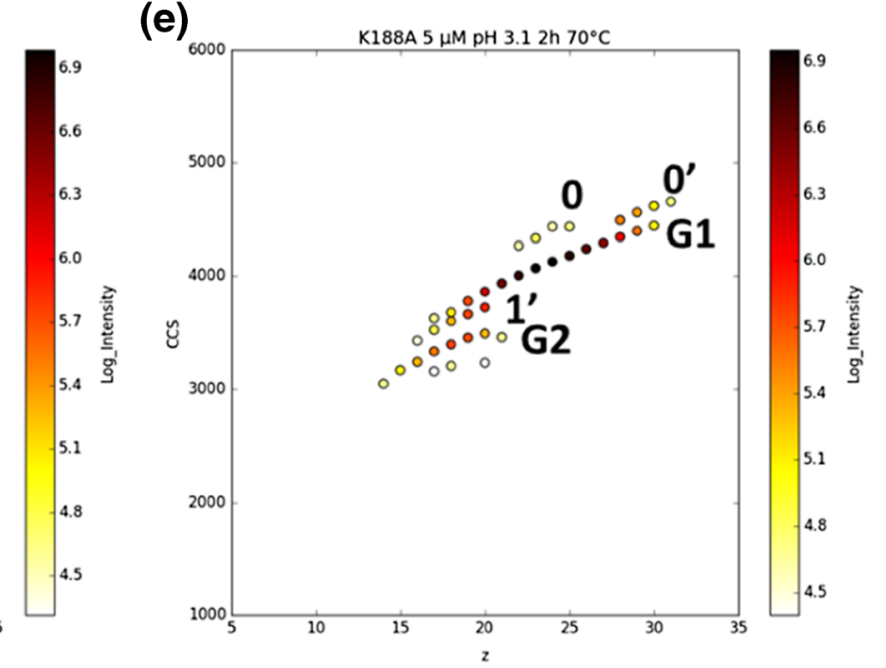

(f)

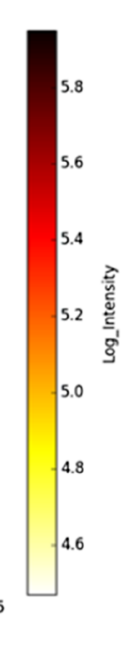

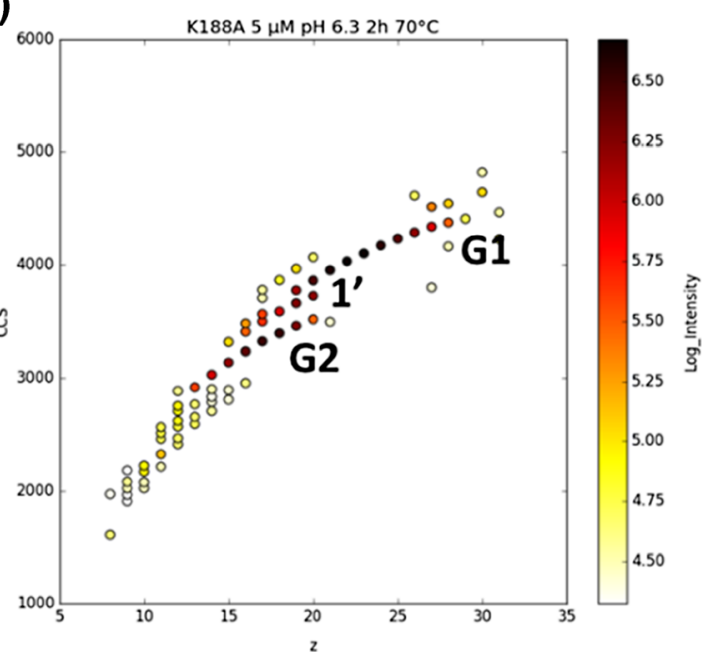

Figure 5. $\Omega(\mathrm{z})$ plots of the OvPrP I208M before (a) and after heating at $70^{\circ} \mathrm{C}$ for $2 \mathrm{~h}$ at $\mathrm{pH} 3.1$ (b) or $6.3(\mathbf{c}) . \Omega(\mathrm{z})$ plots of the OvPrP $\mathrm{K} 188 \mathrm{~A}$ before (d) and after heating at $70{ }^{\circ} \mathrm{C}$ for $2 \mathrm{~h}$ at $\mathrm{pH} 3.1$ (e) or $6.3(\mathrm{f})$ 
Table 2. Display of $\Omega_{\text {(av) }}$ Values of Each Conformer Family for I208M and K188A Mutants Observed After Thermal Unfolding for $2 \mathrm{H}$ at $70{ }^{\circ} \mathrm{C}$

\begin{tabular}{|c|c|c|c|c|c|c|}
\hline Conformer family & $\begin{array}{l}\text { K188A control } \\
\operatorname{CCS}_{(\text {av) }} \AA^{2}\end{array}$ & $\begin{array}{l}\mathrm{K} 188 \mathrm{~A} 2 \mathrm{~h} 70{ }^{\circ} \mathrm{C} \mathrm{pH} 3.1 \\
\mathrm{CCS}_{(\mathrm{av})} \AA^{2}\end{array}$ & $\begin{array}{l}\mathrm{K} 188 \mathrm{~A} 2 \mathrm{~h} 70{ }^{\circ} \mathrm{C} \mathrm{pH} 6.3 \\
\mathrm{CCS}_{(\mathrm{av})} \AA^{2}\end{array}$ & $\begin{array}{l}\text { I208M control } \\
\operatorname{CCS}_{(\mathrm{av})} \AA^{2}\end{array}$ & $\begin{array}{l}\mathrm{I} 208 \mathrm{M} 2 \mathrm{~h} 70^{\circ} \mathrm{C} \mathrm{pH} 3.1 \\
\mathrm{CCS}_{(\text {av) }} \AA^{2}\end{array}$ & $\begin{array}{l}\mathrm{I} 208 \mathrm{M} 2 \mathrm{~h} 70^{\circ} \mathrm{C} \mathrm{pH} 6.3 \\
\mathrm{CCS}_{(\mathrm{av})} \AA^{2}\end{array}$ \\
\hline 0 & & 4548 & 3925 & & 4246 & \\
\hline $0^{\prime}$ & & 4367 & & & 4498 & \\
\hline $1^{\prime}$ & & 3672 & 3632 & & & 3652 \\
\hline G1 & 4086 & 4103 & 4069 & 4076 & 4016 & 4023 \\
\hline $\mathrm{G} 2$ & 3280 & 3376 & 3294 & 3298 & 3323 & 3325 \\
\hline G3 & 2878 & & & 2962 & & \\
\hline
\end{tabular}

plots when samples were heated. Thus, we observed the reduction of the CSD of conformer families, the appearance of additional conformer families (e.g., conformer families $0,0^{\prime}$, and $1^{\prime}$ ), the modification of ratio intensities of conformational ensembles such as for G3, which was shown to increase in intensity compared with G2 for both I208M and K188A mutants at pH 6.3 (see Fig. 5). To annotate the conformer families observed after thermal unfolding, we used the $\Omega_{(\mathrm{av})}$ values of conformer families reported in Table 2. These results suggest that structure expansion, collapse, and redistribution of conformer equilibrium occurred upon thermal denaturation. Thus, with the view to define whether thermal denaturation in ammonium acetate had led to changes in secondary structures, FTIR-ATR spectra were recorded for samples before and after heating. Surprisingly, FTIR-ATR spectra were identical for the two experimental conditions tested (Figure 6 of Supplementary Material). This suggests that secondary structure content is unchanged after thermal denaturation, whereas conformational landscape is modified. This is in agreement with the fact that after heating at $70{ }^{\circ} \mathrm{C}$ and cooling down to $20^{\circ} \mathrm{C}$, PrP monomers completely recover their secondary structures, indicating that unfolding of the globular C-terminal part of PrP is reversible [22]. This assumption is true for protein concentration below $10 \mu \mathrm{M}$. This result clearly demonstrates that heating promotes conformational changes but does not alter the secondary structures. This is in striking contrast to data reported by Hilton's group for $\beta$-sheet rich SyPrP for which the FTIR ATR data undoubtedly show a different profile compared with $\alpha$ helices rich structure [14]. Knowing that mobility profile of the pathologic form of the SyPrP is nearly identical to the "cellular" form discrepancy observed with SyPrP is probably linked to the condition of oligomer formation. After all, the question here is whether additional conformer families observed upon heating are unfolding intermediates or not

\section{Conclusion}

We demonstrate that in-depth analysis of mobility properties was possible by using our home-made program that allowed the accurate detecting of low conformer families. Since our procedure is based on peak detection by Driftscope software, we carefully validated the correctness of Driftscope peak detection, annotation, and quantification by using Gaussian fitting of raw data. This procedure allowed revealing the plasticity of PrP ARQ with demonstration that PrP ARQ and mutants are represented by at least three conformer families with mobility profiles that can be used to differentiate them. Our data also demonstrate that PrPs display a strong plasticity borne by the two domains and strongly influenced by the 103-124 hydrophobic region. While $\mathrm{pH}$ has a marginal effect on conformational landscape, protein concentration can affect the general conformational landscape at low protein concentration. At the last thermal unfolding of the initial monomer reveals that reorganization of conformational landscape both in terms on nature of conformer family and in terms of intensities is observed. Further experiments are now needed to shed light on the biological role of specific conformers upon prion pathogenicity. Our study also continues with the analysis of oligomer properties by ion mobility.

\section{Acknowledgments}

The authors want to warmly thank Delphine Onidas for the recording and processing of the FTIR ATR data.

\section{References}

1. Giles, K., Pringle, S.D., Worthington, K.R., Little, D., Wildgoose, J.L., Bateman, R.H.: Applications of a traveling wave-based radio-frequencyonly stacked ring ion guide. Rapid Commun. Mass Spectrom. 18, 24012414 (2004)

2. Smith, D.P., Knapman, T.W., Campuzano, I., Malham, R.W., Berryman, J.T., Radford, S.E., Ashcroft, A.E.: Deciphering drift time measurements from traveling wave ion mobility spectrometry-mass spectrometry studies. Eur. J. Mass. Spectrom. (Chichester, Engl.) 15, 113-130 (2009)

3. Williams, J.P., Phillips, H.I., Campuzano, I., Sadler, P.J.: Shape changes induced by N-terminal platination of ubiquitin by cisplatin. J. Am. Soc. Mass Spectrom. 21, 1097-1106 (2010)

4. Hopper, J.T., Oldham, N.J.: Collision induced unfolding of protein ions in the gas phase studied by ion mobility-mass spectrometry: the effect of ligand binding on conformational stability. J. Am. Soc. Mass Spectrom. 20, 1851-1858 (2009)

5. Rand, K.D., Pringle, S.D., Murphy III, J.P., Fadgen, K.E., Brown, J., Engen, J.R.: Gas-phase hydrogen/deuterium exchange in a traveling wave ion guide for the examination of protein conformations. Anal. Chem. 81, 10019-10028 (2009)

6. Abzalimov, R.R., Kaplan, D.A., Easterling, M.L., Kaltashov, I.A.: Protein conformations can be probed in top-down HDX MS experiments utilizing electron transfer dissociation of protein ions without hydrogen scrambling. J. Am. Soc. Mass Spectrom. 20, 1514-1517 (2009)

7. Lorenzi, M., Sylvi, L., Gerbaud, G., Mileo, E., Halgand, F., Walburger, A., Vezin, H., Belle, V., Guigliarelli, B., Magalon, A.: Conformational selection underlies recognition of a molybdoenzyme by its dedicated chaperone. PLoS One 7, e49523 (2012)

8. Atmanene, C., Wagner-Rousset, E., Malissard, M., Chol, B., Robert, A., Corvaia, N., Van Dorsselaer, A., Beck, A., Sanglier-Cianferani, S.: Extending mass spectrometry contribution to therapeutic monoclonal antibody 
lead optimization: characterization of immune complexes using noncovalent ESI-MS. Anal. Chem. 81, 6364-6373 (2009)

9. Kaaki, W., Woudstra, M., Gontero, B., Halgand, F.: Exploration of CP12 conformational changes and of quaternary structural properties using electrospray ionization traveling wave ion mobility mass spectrometry. Rapid Commun. Mass Spectrom. 27, 179-186 (2013)

10. Halgand, F., Habchi, J., Cravello, L., Martinho, M., Guigliarelli, B., Longhi, S.: Dividing to unveil protein microheterogeneities: traveling wave ion mobility study. Anal. Chem. 83, 7306-7315 (2011)

11. Breuker, K., McLafferty, F.W.: Stepwise evolution of protein native structure with electrospray into the gas phase, $10(-12)$ to $10(2)$ s. Proc. Natl. Acad. Sci. U. S. A. 105, 18145-18152 (2008)

12. Borysik, A.J., Kovacs, D., Guharoy, M., Tompa, P.: Ensemble methods enable a new definition for the solution to gas-phase transfer of intrinsically disordered proteins. J. Am. Chem. Soc. 137, 13807-13817 (2015)

13. Fenn, L.S., McLean, J.A.: Simultaneous glycoproteomics on the basis of structure using ion mobility-mass spectrometry. Mol. Biosyst. 5, 12981302 (2009)

14. Hilton, G.R., Thalassinos, K., Grabenauer, M., Sanghera, N., Slade, S.E., Wyttenbach, T., Robinson, P.J., Pinheiro, T.J., Bowers, M.T., Scrivens, J.H.: Structural analysis of prion proteins by means of drift cell and traveling wave ion mobility mass spectrometry. J. Am. Soc. Mass Spectrom. 21, 845-854 (2010)

15. Prusiner, S.B.: Prions. Proc. Natl. Acad. Sci. U.S.A. 95, 13363-13383 (1998)

16. Prusiner, S.B.: Novel proteinaceous infectious particles cause scrapie. Science 216, 136-144 (1982)

17. Reixach, N., Deechongkit, S., Jiang, X., Kelly, J.W., Buxbaum, J.N.: Tissue damage in the amyloidoses: transthyretin monomers and nonnative oligomers are the major cytotoxic species in tissue culture. Proc. Natl. Acad. Sci. U. S. A. 101, 2817-2822 (2004)

18. Stefani, M., Dobson, C.M.: Protein aggregation and aggregate toxicity: new insights into protein folding, misfolding diseases and biological evolution. J. Mol. Med. (Berlin) 81(678-699) (2003)

19. Ross, C.A., Poirier, M.A.: Protein aggregation and neurodegenerative disease. Nat. Med. (10 Suppl.) S10-17 (2004)

20. Riek, R., Hornemann, S., Wider, G., Glockshuber, R., Wuthrich, K.: NMR characterization of the full-length recombinant murine prion protein, $\mathrm{mPrP}(23-231)$. FEBS Lett. 413, 282-288 (1997)

21. Eghiaian, F., Grosclaude, J., Lesceu, S., Debey, P., Doublet, B., Treguer, E., Rezaei, H., Knossow, M.: Insight into the PrPC->PrPSc conversion from the structures of antibody-bound ovine prion scrapie-susceptibility variants. Proc. Natl. Acad. Sci. U. S. A. 101, 10254-10259 (2004)

22. Rezaei, H., Eghiaian, F., Perez, J., Doublet, B., Choiset, Y., Haertle, T., Grosclaude, J.: Sequential generation of two structurally distinct ovine prion protein soluble oligomers displaying different biochemical reactivities. J. Mol. Biol. 347, 665-679 (2005)
23. Rezaei, H., Marc, D., Choiset, Y., Takahashi, M., Hui Bon Hoa, G., Haertle, T., Grosclaude, J., Debey, P.: High yield purification and physico-chemical properties of full-length recombinant allelic variants of sheep prion protein linked to scrapie susceptibility. Eur. J. Biochem. 267, 2833-2839 (2000)

24. Chakroun, N., Fornili, A., Prigent, S., Kleinjung, J., Dreiss, C.A., Rezaei, H., Fraternali, F.: Decrypting prion protein conversion into a beta-rich conformer by molecular dynamics. J. Chem. Theory Comput. 9, 24552465 (2013)

25. Chakroun, N., Prigent, S., Dreiss, C.A., Noinville, S., Chapuis, C., Fraternali, F., Rezaei, H.: The oligomerization properties of prion protein are restricted to the H2H3 domain. FASEB J. 24, 3222-3231 (2010)

26. Eghiaian, F., Daubenfeld, T., Quenet, Y., van Audenhaege, M., Bouin, A.P., van der Rest, G., Grosclaude, J., Rezaei, H.: Diversity in prion protein oligomerization pathways results from domain expansion as revealed by hydrogen/deuterium exchange and disulfide linkage. Proc. Natl. Acad. Sci. U. S. A. 104, 7414-7419 (2007)

27. Prigent, S., Rezaei, H.: PrP assemblies: spotting the responsible regions in prion propagation. Prion 5, 69-75 (2011)

28. Shvartsburg, A.A., Smith, R.D.: Fundamentals of traveling wave ion mobility spectrometry. Anal. Chem. 80, 9689-9699 (2008)

29. Ruotolo, B.T., Benesch, J.L., Sandercock, A.M., Hyung, S.J., Robinson, C.V.: Ion mobility-mass spectrometry analysis of large protein complexes. Nat. Protoc. 3, 1139-1152 (2008)

30. Bush, M.F., Campuzano, I.D., Robinson, C.V.: Ion mobility mass spectrometry of peptide ions: effects of drift gas and calibration strategies. Anal. Chem. 84, 7124-7130 (2012)

31. Salbo, R., Bush, M.F., Naver, H., Campuzano, I., Robinson, C.V., Pettersson, I., Jorgensen, T.J., Haselmann, K.F.: Traveling-wave ion mobility mass spectrometry of protein complexes: accurate calibrated collision cross-sections of human insulin oligomers. Rapid Commun. Mass Spectrom. 26, 1181-1193 (2012)

32. Sun, Y., Vahidi, S., Sowole, M.A., Konermann, L.: Protein structural studies by traveling wave ion mobility spectrometry: a critical look at electrospray sources and calibration issues. J. Am. Soc. Mass Spectrom. (2015)

33. Beveridge, R., Covill, S., Pacholarz, K.J., Kalapothakis, J.M.D., MacPhee, C.E., Barran, P.E.: A mass-spectrometry-based framework to define the extent of disorder in proteins. Anal. Chem. 86, 1097910991 (2014)

34. Shi, H., Pierson, N.A., Valentine, S.J., Clemmer, D.E.: Conformation types of ubiquitin $[\mathrm{M}+8 \mathrm{H}] 8+$ ions from water:methanol solutions: evidence for the $\mathrm{N}$ and $\mathrm{A}$ states in aqueous solution. J. Phys. Chem. B 116, 3344-3352 (2012)

35. Ribeiro, A.A., Ortiz, V.: Energy propagation and network energetic coupling in proteins. J. Phys. Chem. B 119, 1835-1846 (2015) 